\title{
PENSAMIENTO E IMAGEN DE LA MUJER EN LAS COMEDIAS CÓMICAS Y SERIAS DE ANTONIO MIRA DE AMESCUA
}

\author{
Tatjana Portnova \\ Universidad de Granada \\ tportnova@ugr.es \\ Luis Gonzaga Roger Castillo \\ Universitat Oberta de Catalunya \\ lrogerc@uoc.edu
}

\section{INTRODUCCIÓN}

$\mathrm{M}$

ira de Amescua se caracteriza por ser un forjador de personajes femeninos en sus obras (Diego, 1974: 19). En varias ocasiones se ha subrayado que sus comedias podrían considerarse feministas, ya que «encierran un mensaje profundo centrado en los derechos de la mujer; lo que demuestra la originalidad y la modernidad de nuestro dramaturgo» (Villanueva Fernández, 1991: 380).

Hablando sobre el escenario general de la época, los personajes femeninos adquieren un papel importante en el teatro del Siglo de Oro (González González, 1995: 69). Manuel Diago (1995: 117) investiga sobre el desarrollo del personaje femenino en el teatro español y destaca que este va a adquirir protagonismo bastante temprano, ya en el siglo XVI. El autor analiza con atención las comedias de Juan de Timoneda y concluye que el escritor crea obras más inclinadas al lado de la mujer que al del hombre.

Aparte de Timoneda, encontramos otros ejemplos donde la mujer desempeña un papel que le permite luchar por sus derechos y comportarse de una manera muy sorprendente para la época. Miguel de Cervantes (1967: 3) en El juez de los divorcios crea el personaje de Mariana, que quiere divorciarse de su marido viejo y que «muestra una sorprendente actitud moderna hacia el matrimonio» (Wilson y Moir, 2001: 81). Tirso de Molina - contemporáneo de Mira de Amescua - escribe multitud de comedias donde las mujeres aparecen como poseedoras del carácter masculino, jugando irónicamente con contrastes de caracteres de los 
sexos (Wilson y Moir, 2001: 170). García Sánchez (1998: 240) ha destacado que el lema de varias comedias de Mira de Amescua es «amor, ingenio y mujer», considerando a las mujeres en sí mismas como ingeniosas y capaces de conseguir cualquier cosa cuando están enamoradas.

El objetivo del presente trabajo es establecer las diferencias que Mira de Amescua muestra en el pensamiento y la imagen de la mujer, dependiendo de si se trata de una obra seria o una obra cómica. Nos hemos centrado principalmente en los personajes femeninos protagonistas en mayor o menor grado, dejando aparte los personajes secundarios (criadas, pastoras, graciosas), ya que estos tienen una función diferente - por ejemplo, según Caballero Méndez (2003: 334), los graciosos suelen ser portadores de valores opuestos, aunque complementarios, a los de su amo-.

El análisis se lleva a cabo sobre las siguientes comedias cómicas: Amor, ingenio y mujer, Cuatro milagros de amor, La Fénix de Salamanca, La tercera de si misma, La ventura de la fea, No hay burlas con las mujeres y Galán, valiente y discreto; y en las siguientes comedias serias: El arpa de David, El esclavo del demonio, La mesonera del cielo, No hay dicha ni desdicha hasta la muerte, La vida y muerte de la monja de Portugal, El hombre de mayor fama y La rueda de la fortuna.

\section{LA DEFINICIÓN DE LA COMEDIA EN EL ÁMBITO ESPAÑOL Y TEORÍA DE LA COMEDIA: \\ LA PROBLEMÁTICA DE LA DEFINICIÓN DE COMEDIA Y DIVISIÓN EN SUBGÉNEROS}

Hay que precisar el significado del término literario «comedia», problemático en el contexto del teatro español del Siglo de Oro según indican varios investigadores. Así, Elder Olson y Bruce Wardropper (1978: 189) señalan el dilema de la nomenclatura y la identificación de la comedia en el Siglo de Oro: «En el siglo XVII, pues, comedia equivalía a drama. Desgraciadamente, se conservó al mismo tiempo el sentido clásico de la palabra, especialmente en la obra de los preceptistas. Con ello, la palabra resultaba ambigua, significando a la vez teatro (el todo) y comedia (la parte)».

En este trabajo utilizaremos la distinción entre «comedias serias» y «comedias cómicas», partiendo de la clasificación que propone Ignacio Arellano (1995: 255276) en la introducción general a la obra de Mira de Amescua. La elección de dicha clasificación - y no, por ejemplo, la de Valbuena Prat (1974) que también menciona Arellano (1995: 254), consistente en la división en comedias bíblicas, de santos, palaciegas, etc.- es debida al objetivo de analizar la dependencia del nivel de seriedad de la obra en correlación con la imagen de la mujer que presenta.

Edward M. Wilson y Duncan Moir (2001: 93) destacan que fue Lope de Vega quien apuntó en su Arte nuevo de hacer comedias en este tiempo la diferencia 
entre el género de la comedia y la tragedia y describió los elementos básicos de estos dos tipos de obras. Lope de Vega (1968: 373) señala:

Por argumento la tragedia tiene la historia, y la comedia, el fingimiento, que nos indica, aunque en una formulación bastante simplificada, que en la comedia el mundo está representado «al revés»; metáfora que suelen mencionar varios investigadores escribiendo sobre la comedia española del Siglo de Oro. Dicha deformación e inversión la experimenta el personaje femenino, que en la realidad social del siglo XVII ejerció escaso papel. De las mujeres en la época se sabe que por lo general, sólo se ocupaban de sus labores o de los rezos. Además en la vida pública no importaban nada de nada (Rozas Marín, 1996: 511).

Entre los estudios sobre las mujeres en la literatura del Siglo de Oro hay investigaciones generales dedicadas a la distinta imagen de la mujer en las obras serias y en las cómicas. Luis González González (1995: 42) subraya que en las obras serias la mujer es «depositaria del honor familiar», mientras en las cómicas es «la que controla el escenario [...] la transgresora de un orden social inventado por los hombres y en el que no se siente libre». Teresa Ferrer Valls (1998: 1) analiza la diferencia entre el género cómico y el serio, destacando que el cómico permite situar en el centro de la acción «personajes femeninos en situaciones más permisivas que el drama».

\section{La imagen de la mujer en las comedias cómicas de Mira de Amescua}

\subsection{LOS TEMAS DOMINANTES}

En las siete comedias estudiadas, la relación hombre-mujer pasa a ser la base de la comedia. El enamoramiento de una mujer y la subsiguiente «conquista» del hombre amado o simplemente la búsqueda, por parte de la mujer, del marido apropiado, se convierten en los temas principales. En Galán, valiente y discreto la trama principal queda constituida por la elección de esposo por parte de la duquesa con la ayuda de su criada Porcia. Algo parecido encontramos en Cuatro milagros de amor: la dama Ana busca un marido y con la ayuda de su criada Lucrecia pone a los pretendientes a prueba para después elegir el más digno. En La tercera de si misma, a lo largo de tres actos Lucrecia recurre a varias astucias para conseguir su objetivo: el duque de Mantua. La protagonista de Amor, ingenio y mujer, debiendo esconder su sexo por causas relativas a la herencia al trono, inventa ardides para poder comunicarse con su elegido Enrique. La Fénix de Salamanca nos cuenta la historia de doña Mencía, que se enamora en Salamanca de don Garcerán y lo persigue, en una actitud claramente masculina, por toda España hasta que le abre sus sentimientos. 
Es más compleja la trama de las dos comedias restantes, pero también giran alrededor del amor y el casamiento. En No hay burlas con las mujeres, doña Arminda está enamorada de don Lope, pero tras una serie de enredos se despide de ella. La segunda línea amorosa es la de doña Laura, que viene con don Diego, pero de repente se enamora de don Jacinto. Sigue otra serie de enredos y la comedia termina con dos casamientos, de Laura con Jacinto y de Arminda con Diego. También en La ventura de la fea hay dos mujeres y con esto dos líneas de trama. Ángela y Francisca son hermanas, la primera es bella y la segunda fea. Pensando demasiado en sí misma, Ángela rechaza la proposición de matrimonio del viejo Valdivia. Su hermana Francisca la acepta e inmediatamente el viejo muere dejando a su viuda rica. Los tres pretendientes de Ángela ahora piden la mano de Francisca y ella elige a quien siempre ha querido (don Juan).

Es interesante destacar que en Cuatro milagros de amor y La ventura de la $f e a$, Mira de Amescua presta atención a la fealdad de la mujer de una manera no común: los personajes femeninos que adoptan tal apariencia no son unos seres desdichados, sino más bien al revés. La fealdad de la mujer no se trata como algo negativo, porque las mujeres feas están seguras de sí mismas y consiguen encontrar la felicidad con las personas que les gustan.

\subsection{El CASAmiento COMO OBJetivo de UnA MUJeR}

Otro elemento común que encontramos en las comedias cómicas es el deseo de casarse con la persona amada. Cada una de las siete comedias termina con el casamiento de la mujer protagonista con el amado; en la mayoría de los casos, después de un largo camino de astucias por parte de la mujer que llevará finalmente a este casamiento. La única comedia donde se observa una excepción es La tercera de si misma, donde Lucrecia no consigue el amor del duque y le deja voluntariamente casarse con la mujer a quien verdaderamente ama (Porcia).

El objetivo del casamiento responde a la clara realidad sociológica del momento. Los investigadores señalan que en la vida de los siglos XVI y XVII «una de las cosas que más deseaban las mujeres, aparte de ser hermosas, era casarse» (Vigil, 1986: 78). Encontramos en diversas comedias las discusiones sobre el casamiento. Las dos más evidentes son las que abren la acción en Galán, valiente $y$ discreto y en Cuatro milagros de amor. Ambos ejemplos manifiestan el referido concepto del mundo «al revés». Por un lado, la posibilidad por la parte de una mujer de elegir a un marido, porque en la sociedad de la época «las mujeres no podían elegir, generalmente, al que iba a ser su marido, pues ya lo hacían por ellas sus padres o tutores, y para ello se fijaban en un caballero que tuviera nobleza y fortuna» (Rozas Marín, 1996: 512). Por otro lado, en vez de demostrar su interés por el casamiento, las damas nobles expresan su rechazo al matrimonio. Ambas (la 
duquesa de Mantua en Galán, valiente y discreto y doña Ana en Cuatro milagros de amor) dicen que «han de casarse», lo que indica la necesidad del casamiento, pero no su deseo. En ambos textos las damas van a elegir de entre los hombres, que en cierta manera les gustan, al más digno. De esta manera, surge la cuestión de la importancia de que el marido sea estimable, mientras que la del amor se reduce, cosa que está fuera de la norma, porque la imagen clásica de una mujer en la comedia del Siglo de Oro es la de quien se enamora y persigue su objetivo, como sucede, por ejemplo, en La tercera de sí misma.

En otras comedias podemos encontrar personajes femeninos que eligen y evalúan la «calidad» de los maridos, como la condesa Porcia de La tercera de si misma, o Ángela en La ventura de la fea. Una de las líneas argumentales de $L a$ Fénix de Salamanca es la de Alejandra, que tiene que casarse por causas económicas con un hombre mayor y rico. La mujer no lo acepta, porque es un matrimonio desigual y además no ama a su prometido. La joven se rebela contra lo que le prescribe la sociedad, aunque se entiende que en realidad no tiene otra opción: el galán a quien ama no es de un estrato social suficientemente acomodado. De tal modo, las mujeres de las comedias cómicas se suelen rebelar contra las reglas imperantes en la sociedad: el casamiento queda como algo imprescindible para una mujer, pero adquiere libertad en el momento de elegir un marido para sí.

\subsection{El DESEQUILIBRIO ENTRE HOMBRE Y MUJER COMO PROTAGONISTAS}

Otro aspecto destacable de las comedias cómicas es el desequilibrio evidente entre los personajes masculinos y femeninos. Como señala González González, en las comedias «los personajes masculinos aparecen como más planos, sin iniciativa, son más simples y a veces poseen los defectos que habitualmente se han atribuido a las mujeres, volubilidad, etc.» (1995: 61). Entre las siete comedias estudiadas no hay ninguna donde el hombre desarrolle el papel de protagonista o - como mínimo - de un personaje con la misma fuerza que la mujer que aparece como protagonista de la obra. En todas estas (aparte de La ventura de la fea y quizá No hay burlas con las mujeres) son las mujeres quienes eligen al hombre para sí y la trama se desarrolla alrededor de sus ingenios para obtener su objetivo.

Al mismo tiempo, encontramos muchos ejemplos de hombres que están caracterizados por sus defectos. Así, por ejemplo, en Cuatro milagros de amor los pretendientes de las damas son uno necio, otro cobarde, el tercero, avaro y el cuarto, un descuidado de sí; o bien son débiles y contradicen la imagen estereotipada de un hombre valiente y vencedor. El mejor ejemplo lo encontramos en No hay burlas con las mujeres, donde la protagonista, doña Arminda, se venga de Lope - su antiguo amante, que la ha engañado hablando de amor con otra- matándolo de un disparo de pistola. 
En las comedias cómicas se establece la imagen de la mujer protagonista con un carácter fuerte y de un hombre que no llega a destacar y que además, en muchas ocasiones, posee unos rasgos de carácter negativos.

\subsection{Mujer DisfrazADA DE HOMBRE}

Carmen Bravo-Villasante escribe en su libro dedicado a los estudios sobre la mujer vestida de hombre en el teatro español:

Existe en la literatura española, especialmente en el teatro del siglo XVII, una multitud de mujeres atrevidas que, bien por un motivo o por otro, adoptan el indumento varonil y se lanzan a una aventura arriesgada en busca de su felicidad. [...] atraviesan bizarras la escena [...] defendidas por la doble arma de su espada y su astucia (1976: 3).

Después hace referencia a que en la literatura española existen dos figuras principales: la «mujer enamorada» y la «heroica-guerrera». La primera, «muy femenina y normal, y la segunda, hombruna y de una amoralidad casi siempre patológica» (Bravo-Villasante, 1976: 3). La obra de Mira de Amescua tampoco carece de tales personajes. Dentro de las comedias analizadas encontramos $L a$ Fénix de Salamanca, Amor, ingenio y mujer y La tercera de sí misma, donde las mujeres protagonistas coinciden con la descripción de la mujer enamorada que somete Bravo-Villasante.

Si comparamos a Lucrecia de La tercera de sí misma y a doña Mencía de La Fénix de Salamanca se aprecia una diferencia evidente entre ellas: en un caso una consigue su objetivo y en el otro no. Lucrecia, en comparación con doña Mencía, es mucho más varonil, mientras que doña Mencía de La Fénix de Salamanca no carece de feminidad. Argente del Castillo subraya en el personaje de doña Mencía que «reivindica la capacidad de poder actuar y arrastra a las otras dos mujeres tras ella, pero su carácter varonil no pasa de esta actitud, ella aspira a triunfar con sus armas de mujer y así, cuando lo necesita, utiliza todo su encanto femenino» (1996: 129). En cambio a Lucrecia el amor la ha convertido en hombre, no solo por fuera, sino también por dentro y tal mujer no carecerá de interés para la mayoría de los hombres.

La diferencia de la función del disfraz varonil en Amor, ingenio y mujer es que aquí la obra se deja llevar por la realidad de la vida española de la época (Caballero Méndez, 2003: 333), añadiendo un trasfondo histórico de mayor seriedad. La protagonista, la infanta Matilde, esconde su sexo femenino, apareciendo como el infante Carlos por cuestiones relativas a la herencia al trono: su padre no tiene hijos y para mantener la Corona desde la niñez educa a la infanta como a un varón. Matilde obedece a su padre, juega el papel social que le han prescrito, pero 
al enamorarse tiene que mostrar astucia para abrir sus sentimientos al elegido. Inventa a una hermana gemela y, por otra parte, consigue que se cambie la ley sálica. De tal manera, el disfraz varonil desempeña aquí una función más bien social; aunque por dentro de este se esconde una imagen femenina muy extraordinaria que puede desarrollar perfectamente el papel del hombre.

\section{La imagen de la mujer en las comedias serias de Mira de Amescua}

\subsection{Los TEMAS DOMINANTES}

Hemos establecido que, en las comedias cómicas, el amor es el tema principal, el eje de la trama. Algo diferente sucede en las comedias serias: el amor sigue estando presente, pero apenas tiene la función vehicular de la obra. En las siete comedias serias estudiadas en este trabajo encontramos un amplio abanico de temas principales.

Así, El esclavo del demonio se basa en la leyenda de fray Gil de Santarem y el tema principal es su tentación y el «pacto con el diablo». Las comedias $L a$ mesonera del cielo y La vida y muerte de la monja de Portugal nos presentan un caso similar: la primera tiene por sujeto la leyenda de Abraham, un santo ermitaño del siglo IV, y su sobrina María; la segunda es una comedia hagiográfica, aunque la protagonista aquí es falsa e inventada, pero la base de la obra también recae sobre la idea de la tentación, de aquí la seriedad de la comedia. El acercamiento a la realidad se refuerza por medio de la introducción de un trasfondo histórico, ya que se mencionan los acontecimientos de la batalla con Inglaterra y de la Armada Invencible.

El Arpa de David, La rueda de la fortuna y No hay dicha ni desdicha hasta la muerte tienen como punto de partida el tema de los cambios de la fortuna. Como destaca Villanueva Fernández (1991: 367) para las «piezas dramáticas» de Mira de Amescua el tema de la fortuna es una especie de origen para la producción. El arpa de David narra al estilo barroco la «inestabilidad de la fortuna y de los bienes terrenales» (García Sánchez, 2001: 99); asimismo, se observa un gran influjo bíblico. También en No hay dicha ni desdicha hasta la muerte encontramos en segundo plano el trasfondo histórico: los acontecimientos tienen lugar en la época de las luchas entre los hijos de Alfonso III de Asturias (Presotto, 2009: 569). Como señala Fernández Labrada (2001: 305), El hombre de mayor fama es una obra que sintetiza las hazañas de Hércules, centrándose en sus relaciones amorosas. Es importante que el tema de amor no se presenta en primer plano, sino que comparte el argumento con los acontecimientos míticos.

Por lo tanto, en las comedias serias hay una tendencia a los temas mitológicos y religiosos, así como al de la fortuna. El trasfondo histórico ocupa un lugar 
relevante. Estas conclusiones van en la línea de lo que destacó Ignacio Arellano señalando que la obra de Mira de Amescua se caracteriza por «el cultivo de diversos subgéneros y la escasez de piezas cómicas [...] más inclinado a la comedia seria de lección moral» (1995: 253).

\subsection{LA ACTITUd DE LAS MUJERES ANTE El CASAMIENTO EN LAS COMEDIAS SERIAS}

Si en las comedias cómicas nos encontrábamos con mujeres que eligen a un hombre y consiguen que sea su marido, en las comedias serias, en la mayoría de los casos, es el hombre el que elige a la mujer, sea el galán, el padre o el mismo rey.

En El esclavo del demonio y La mesonera del cielo encontramos a dos mujeres (Lisarda y María correspondientemente) que se rebelan contra el matrimonio. La primera lo hace para defender sus derechos y protestar contra la voluntad de su padre, acercándose a las protagonistas de las comedias serias (puede ser por el carácter fronterizo de esta comedia que, siendo seria, incorpora elementos cómicos).

El padre de Lisarda quiere casarla con don Sancho, pero Lisarda, enamorada de don Diego, no obedece. Este comportamiento se encuentra bajo el ojo crítico de la sociedad; algo que no encontramos en las comedias cómicas. Además, se elogia el carácter femenino que posee la hermana de Lisarda, Leonor. Según Villanueva Fernández, Leonor «reúne incontables "virtudes" cristianas: la compresión, la misericordia y el amor (caridad). Un auténtico dechado de perfecciones» (2004: 121). Cuando Lisarda se escapa de su casa, su padre insiste en que Leonor se case ahora con don Sancho y esta, aunque iba a ser monja, lo acepta porque es la voluntad de su padre.

María, en La mesonera del cielo, se opone al casamiento, pero en este caso sin contradecir al subgénero: su comportamiento está justificado por el deseo de servir a Dios. Hay que señalar que, para algunos investigadores, dicha comedia era la causa de atribuirle a Mira de Amescua opiniones misóginas (Villanueva Fernández, 1998: 446).

En el resto de las comedias es el hombre el que toma la decisión. En El arpa de David y en El hombre de mayor fama es el padre quien da la mano de su hija al varón. En La vida y muerte de la monja de Portugal, los padres de don Juan no quieren que se case con María y lo mandan a luchar a Inglaterra, imposibilitando de esta manera el matrimonio que desea su hija. Al final de La rueda de la fortuna el general Felipe elige con quién se va a casar, y elige a la infanta y no a la persa Mitilene en quien también estaba interesado. En No hay dicha ni desdicha hasta la muerte es el rey quien decide a quién dar la mano de Leonor, que antes se encontraba indecisa entre dos pretendientes, don Porcelos y don Vela.

Por lo tanto, en las comedias serias la mujer no decide en el momento de la elección del marido, sino que la decisión la toma su padre o el pretendiente mismo 
o un sujeto de alto estrato social. Aun así, en este desplazamiento de la elección se puede observar cómo se subraya la relación de autoridad entre la figura decisoria o árbitro y la mujer.

\subsection{El DESEQUiLIBRIO ENTRE EL HOMBRE Y LA MUJER COMO PROTAGONISTA}

En comparación con las comedias cómicas, en las serias encontramos pocos ejemplos de fuerte protagonismo femenino que sobresalga o se acerque al del hombre. Aparece solo en las comedias que mantienen ciertos rasgos cómicos (como es el caso de Mitilene en La rueda de la fortuna y Lisarda en El esclavo del demonio) o bien la función de dicho protagonismo es religiosa y didáctico-moral, mediante personajes monjas. En otras comedias la acción gira alrededor del hombre: David en el caso de El arpa de David, don Vela y don Porcelos en No hay dicha ni desdicha hasta la muerte y Hércules en El hombre de mayor fama.

Las mujeres protagonistas de La mesonera del cielo y de La vida y muerte de la monja de Portugal deciden servir a Dios, y la comedia gira alrededor de su camino hasta volverse santas. Lo que nos interesa es la manera de construir este camino por parte del autor y la propia personalidad de dos mujeres que se esconde detrás de su comportamiento en los diversos acontecimientos. Ambas son puestas a prueba por el diablo y no la pasan: una, aunque después de cierta resistencia, cede ante la tentación y tiene relaciones amorosas con Alejandro; otra es un personaje totalmente negativo en el plano religioso, decide ser monja, pero muy pronto se deja vencer por la vanidad y finge vivir una vida santa. En cierto momento se arrepiente, pero ya es tarde y es condenada por la Inquisición. Solamente al final de la comedia, después de su muerte, el hecho de que vea al niño Jesús nos indica su salvación.

Ambas mujeres se presentan en las comedias como unos seres débiles que siguen sus deseos y sin fuerza suficiente para resistir ante el demonio. También es propio de las mujeres en otras comedias tener varios defectos o rasgos de carácter débil en oposición a los hombres, que carecen de ellos (por ejemplo, Bersabé de El arpa de David no muestra vergüenza en la escena donde descubre que el rey la vio bañándose).

Algunas veces hay oposición entre personajes femeninos: uno representa la moral y otro lo contrario. Algo parecido se vio ya en Lisarda y Leonor en El esclavo del demonio. Así son Yole y Diamira. Esta última es el modelo positivo que está dispuesta sacrificarse por el amor, mientras que la primera es el modelo negativo que lleva al héroe por el camino de la degradación. A primera vista parece que Yole tendría que caracterizarse en la misma línea de las mujeres varoniles de las comedias cómicas, pero la diferencia consiste en que la función de una mujer varonil aquí es, en menor parte, unirse con un hombre y, en mayor 
parte, desempeñar la función moralizadora de la comedia, mostrando dos posturas morales ante la vida mediante dos personajes femeninos contrapuestos (Fernández Labrada, 1998: 230).

De esta manera, en las comedias serias el equilibrio de protagonismo se inclina hacia los personajes masculinos, aunque encontramos algunos casos en sentido contrario. La notable importancia de personajes femeninos se explica bien por las intenciones didácticas y morales, o bien por la incorporación de elementos cómicos en la comedia seria.

\subsection{El DisfraZ VARONIL EN EL ESCLAVO DEL DEMONIO Y EL HOMBRE DE MAYOR FAMA}

También en las comedias serias encontramos casos en los que la mujer aparece en el escenario vestida de hombre. Concretamente, en las comedias de El esclavo del demonio y El hombre de mayor fama. Si en las obras cómicas la mujer se disfrazaba de hombre, solía hacerlo - aunque no obligatoriamente - para conseguir su objetivo, que no era otra cosa que el hombre de quien estaba enamorada; pero en las dos comedias mencionadas la función del disfraz es diferente.

En El esclavo del demonio, Lisarda recurre al disfraz varonil como instrumento para vengarse de don Gil, que ha gozado de ella haciéndose pasar por don Diego. De esa manera, el recurso aparece vinculado a la justicia y el honor. Más difíciles son las relaciones que se establecen entre el personaje de la mujer vestida de hombre y la acción principal de la trama en El hombre de mayor fama. Diamira se disfraza de hombre para ir a Italia, donde se encuentra a Hércules, quien la traicionó casándose allí con la hija del rey. La mujer ofendida le persigue, le escribe una carta, pero él no reacciona. Diamira vestida de truhan sigue estando al lado de él en la corte. Al mismo tiempo, Hércules se viste con galas nobles y empieza a comportarse como un rey vago.

Fernández Labrada (1998: 223) interpreta esta escena como el punto culminante de la fidelidad y valentía de Diamira, mientras que Hércules vestido de mujer se encuentra en el momento más bajo de su historia. Por lo tanto, por una parte el disfraz varonil parece seguir la línea argumental ordinaria de la mujer que persigue a su amado, pero por otra sirve para crear una comparación encubierta entre Diamira y Hércules que remite al sentido moral antes mencionado.

\section{ConClusiones}

En las comedias analizadas se observan los cambios en el personaje y la imagen de la mujer dependiendo del subgénero en el que aparece. En primer lugar, hemos establecido que la imagen de la mujer en las comedias cómicas es diferente en comparación con la de las comedias serias. Ante todo, esto queda directamente 
referido al protagonismo de la mujer: si en las primeras la mujer se convierte en el eje de la comedia, en las segundas se queda en un segundo plano, o si se convierte en la protagonista, suele ser una santa que tiene el papel principal en una obra seria por motivos religiosos. Al mismo tiempo, el protagonismo de la mujer está inseparablemente vinculado con el tema del dominio. De tal modo, las comedias cómicas suelen presentar al público situaciones que giran alrededor del amor, con lo que, en concordancia con la teoría del mundo al revés de la comedia, la mujer se presenta en primer plano. Como contrapartida, las comedias serias, sean estas teológicas, sociales o históricas, suelen tener como argumento temáticas relacionadas con la moral. En todos estos casos, el hombre adquiere mayor protagonismo y los personajes femeninos quedan como medios complementarios para trasmitir al público la idea moral de la obra.

En segundo lugar, el tema del casamiento aparece en ambos subgéneros como reflejo de la realidad histórica, siendo de notar una diferencia significativa en el comportamiento de las mujeres ante él. Así, el matrimonio se presenta en ambos casos como algo imprescindible para una mujer, pero en las comedias cómicas la mujer tiene cierta libertad en la elección del marido o como mínimo, si en un principio no tiene posibilidades para elegir, después de haberse rebelado contra la decisión que se le impone, consigue al marido que quiere. En cuanto a las comedias serias, suele ser el hombre el que elige el marido para una mujer, siendo este el padre, el pretendiente o una persona con un estatus social más alto. La mujer en la mayoría de los casos obedece a la decisión del hombre.

En tercer lugar, en las comedias cómicas los personajes femeninos son los que cuentan con más fuerza y virtudes, mientras que los hombres suelen tener más defectos. A su vez, en las comedias serias es el hombre quien se presenta lleno de fuerza o de virtudes y la mujer en muchas ocasiones llega a ser un personaje débil y falto de voluntad. Hay que mencionar que algunos defectos, que suelen tomarse como algo negativo, en las comedias cómicas adquieren una carga de valor diferente. De esta forma, vemos que la fealdad no se manifiesta como un defecto insoslayable, al mismo tiempo que se proclama que lo más importante son las virtudes del alma.

Además, el disfraz varonil también aparece en ambos subgéneros, aunque con ciertas diferencias. En las comedias cómicas su función es conseguir al amado y el objetivo de su uso es provocar la risa, manifestación de la subversión propia de la comedia y del mundo al revés, mientras que en las comedias serias una mujer vestida de hombre suele subordinarse a los objetivos morales de la obra y servir como medio auxiliar para crear una imagen que demuestra al espectador un comportamiento correcto o incorrecto de un cierto personaje. 
BiBLIOGRAFÍA

Arellano, Ignacio (1995). Historia del teatro español del siglo XVII. Madrid: Cátedra.

Argente del Castillo, Concepción (1996). «La mujer entre la confusión y el ingenio. (Apuntes sobre La Fénix de Salamanca)». En Agustín de la Granja y Juan Antonio Martínez Berbel (eds.), Mira Amescua en candelero: actas del Congreso Internacional sobre Mira de Amescua y el teatro español del siglo XVII (Granada, 27-30 octubre de 1994), 1, pp. 115-136.

Bravo-Villasante, Carmen (1976). La mujer vestida de hombre en el teatro español. Madrid: SGEL.

Caballero MÉndez, Ascensión (2003). «Introducción a Amor, ingenio y mujer». En Agustín de la Granja (coord.), Mira de Amescua, Antonio, Teatro completo III. Granada: Universidad de Granada, pp. 329-419.

Diago, Manuel (1995). «La mujer en el teatro profesional del Renacimiento: entre la sumisión y la astucia (A propósito de Las tres Comedias de Joan Timoneda)». Criticón, 63, pp. 103-117.

Diego, Gerardo (1974). «Mira de Amescua, hombre y poeta». $A B C, 19,25$ de junio de 1974 $<$ http://hemeroteca.abc.es/nav/Navigate.exe/hemeroteca/madrid/abc/1974/06/25/019. html> [Consulta: 03/04/2020].

FERnÁNDEZ LABRAdA, Manuel (1998). «Diamira y Yole, dos modelos de mujer para seducir a un héroe (a propósito de El hombre de mayor fama, de Mira de Amescua)». En Juan Antonio Martínez Berbel y Roberto Castilla Pérez (eds.), Las mujeres en la sociedad española del siglo de oro: ficción teatral y realidad histórica. Actas del II coloquio del Aula-Biblioteca «Mira de Amescua» celebrado en Granada-Úbeda del 7 al 9 de marzo de 1997 y cuatro estudios clásicos sobre el tema. Granada: Universidad de Granada, pp. 217-231.

FERnÁNDEZ LABRADA, Manuel (2001). «Introducción a El hombre de mayor fama». En Agustín de la Granja (coord.), Mira de Amescua, Antonio. Teatro completo I. Granada: Universidad de Granada, pp. 305-307.

Ferrer Valls, Teresa (1998). «Mujer y escritura dramática en el Siglo de Oro: del acatamiento a la réplica de la convención teatral». Cuadernos Escénicos, 5, pp. 11-32.

García SÁnchez, María Concepción (1998). «Actitudes y comportamientos femeninos en algunas comedias de Mira de Amescua». En Juan Antonio Martínez Berbel y Roberto Castilla Pérez (eds.), Las mujeres en la sociedad española del Siglo de Oro: ficción teatral y realidad histórica. Actas del II coloquio del Aula-Biblioteca «Mira de Amescua» celebrado en Granada-Úbeda del 7 al 9 de marzo de 1997 y cuatro estudios clásicos sobre el tema. Granada: Universidad de Granada, pp. 233-248.

García SÁnChez, María Concepción (2001). «Introducción a Arpa de David». En Agustín de la Granja (coord.), Mira de Amescua, Antonio, Teatro completo I. Granada: Universidad de Granada, pp. 99-103.

GonzÁlez González, Luis (1995). «La mujer en el teatro del Siglo de Oro español». Teatro: Revista de Estudios Teatrales, 6-7, pp. 41-70.

Mira de Amescua, Antonio (2001). Teatro completo. Granada: Universidad de Granada / Diputación de Granada, vol. I, pp. 97-206; 303-380. 
Mira de Amescua, Antonio (2002). Teatro completo. Granada: Universidad de Granada / Diputación de Granada, vol. II, pp. 437-561.

Mira de Amescua, Antonio (2003). Teatro completo. Granada: Universidad de Granada / Diputación de Granada, vol. III, pp. 327-419.

Mira de Amescua, Antonio (2004). Teatro completo. Granada, Universidad de Granada /

Diputación de Granada, vol. IV, pp. 113-240; 431-564; 565-666.

Mira de Amescua, Antonio (2005). Teatro completo. Granada: Universidad de Granada /

Diputación de Granada, vol. V, pp. 263-355; 555-641.

Mira de Amescua, Antonio (2008). Teatro completo. Granada: Universidad de Granada /

Diputación de Granada, vol. VIII, pp. 381-490.

Mira de Amescua, Antonio (2009). Teatro completo. Granada: Universidad de Granada /

Diputación de Granada, vol. IX, pp. 135-245; 569-686.

Mira de Amescua, Antonio (2011). Teatro completo. Granada: Universidad de Granada /

Diputación de Granada, vol. XI, pp. 277-404.

Mira De Amescua, Antonio (2012). Teatro completo. Granada: Universidad de Granada /

Diputación de Granada, vol. XII, pp. 489-630.

Olson, Elder y Bruce WARDROPPER (1978). Teoría de la comedia. Barcelona: Ariel.

PRESOTto, Marco (2009). «Introducción a No hay dicha ni desdicha hasta la muerte». En Agustín de la Granja (coord.), Mira de Amescua, Antonio. Teatro completo. Granada: Universidad de Granada / Diputación de Granada, vol. IX, pp. 569-686.

Rozas MARÍN, Dolores (1996). «La falsa apariencia de Lucrecia en Cuatro milagros de amor, de Mira de Amescua». En Agustín de la Granja y Juan Antonio Martínez Berbel (eds.), Mira Amescua en candelero: actas del Congreso Internacional sobre Mira de Amescua y el teatro español del siglo XVII (Granada, 27-30 octubre de 1994), vol. I, pp. 511-520.

Valbuena Prat, Ángel (1974). El teatro español en su Siglo de Oro. Barcelona: Planeta.

VeGA, Lope de (1968). Selección de obras de Lope de Vega. Bilbao: Moretón.

VIGIL, Mariló (1986). La vida de las mujeres en los siglos XVI y XVII. Madrid: Siglo XXI.

Villanueva Fernández, Juan Manuel (1991). «El teatro de Mira de Amescua». RILCE, 7 , pp. 363-381.

Villanueva Fernández, Juan Manuel (1998). «¿Fue misógino Mira de Amescua?». En Juan Antonio Martínez Berbel y Roberto Castilla Pérez (eds.), Las mujeres en la sociedad española del siglo de oro: ficción teatral y realidad histórica. Actas del II coloquio del Aula-Biblioteca «Mira de Amescua» celebrado en Granada-Úbeda del 7 al 9 de marzo de 1997 y cuatro estudios clásicos sobre el tema. Granada: Universidad de Granada, pp. 429-453.

Villanueva FernÁNDEZ, Juan Manuel (2004). «Introducción a El esclavo del demonio». En Agustín de la Granja (coord.), Mira de Amescua, Antonio. Teatro completo. Granada: Universidad de Granada, vol. IV, pp. 115-240.

Wilson, Edward M. y Duncan MorR (2001). Historia de literatura española, 3. Siglo de Oro: teatro. Barcelona: Ariel. 


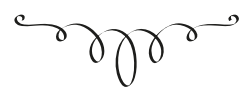

Pensamiento E IMAgen de LA MUJer en LAS COMEDias CÓMicAS y Serias de ANtonio Mira de Amescua

RESUMEN: Los personajes femeninos tienen una presencia importante en las obras teatrales de Antonio Mira de Amescua (1577-1644). Dentro de su obra, recurriendo a la denominación genérica de comedia, como referida a toda producción teatral en el Siglo de Oro, cabe distinguir entre comedias serias y cómicas, atendiendo al tono general de la obra, a las peripecias argumentales y al modo en que concluye. Los personajes femeninos, no obstante, reciben un tratamiento considerablemente diferente, tanto en el pensamiento e imagen sobre la mujer como en la temática a la que sirve de vehículo. La investigación analiza catorce comedias de Mira de Amescua, siete cómicas y siete serias, para extraer el pensamiento, imagen y temática de los personajes femeninos. Se comprueban y contrastan las diferencias existentes entre ambas clases de comedias, presentando una imagen de la mujer mucho más libre en las obras cómicas, llegando incluso en ocasiones a la inversión de roles con el hombre, otorgando el protagonismo a las figuras femeninas y haciendo predominar la libertad de elección en el matrimonio. En las obras serias, en sentido contrario, se observa el predomino de los personajes femeninos como secundarios, la delegación de la elección en el matrimonio en figuras masculinas de autoridad y una asunción de roles convencionales o hagiográficos.

Palabras clave: mujer, pensamiento, imagen, Mira de Amescua, comedia, Siglo de Oro, literatura.

\section{THINKING AND IMAGEN OF THE WOMAN IN COMIC AND SERIOUS COMEDIES} of Antonio Mira de Amescua

ABSTRACT: Female characters have an important presence in the plays of Antonio Mira de Amescua (1577-1644). Using the generic naming of the term «comedy», as referring to all theatrical production in the Spanish Golden Age, we can distinguish in his works serious and comic comedies, following the general tone of a play, the plot and the way in which a play concludes. The female characters, however, receive a considerably different treatment, both in terms of thought and image of women and in the theme surrounding women. The present study analyzes fourteen comedies by Mira de Amescua, seven comic ones and seven serious. Our aim is to extract the thoughts, images and themes around the female characters. We contrast the differences between both classes of comedies, detecting a much freer image of women in comic ones, sometimes even reversing roles with men, giving prominence to female figures and giving them freedom of choice in marriage. In serious works, on the contrary, the roles of female characters are secondary, the delegation of the choice of marriage remains with authoritative male figures, and there is an assumption of conventional or saintly roles.

KeYwords: Woman, Thinking, Image, Mira de Amescua, Comedy, Spanish Golden Age, Literature. 